\title{
Long-term hurricane damage effects on tropical forest tree growth and mortality
}

\author{
Edmund V. J. Tanner, ${ }^{1,4}$ Francisco Rodriguez-Sanchez, ${ }^{1,5}$ John R. Healey, ${ }^{2}$ Robert J. Holdaway, ${ }^{3}$ \\ and Peter J. Bellingham ${ }^{3}$ \\ ${ }^{1}$ Department of Plant Sciences, University of Cambridge, Downing Street, Cambridge CB2 3EA United Kingdom \\ ${ }^{2}$ School of Environment, Natural Resources and Geography, Bangor University, Deiniol Road, Bangor LL57 2 UW United Kingdom \\ ${ }^{3}$ Landcare Research, P.O. Box 69040, Lincoln 7640 New Zealand
}

\begin{abstract}
Hurricane winds can have large impacts on forest structure and dynamics. To date, most evaluations of hurricane impacts have focused on short-term responses after a hurricane, often lacked pre-hurricane measurements, and missed responses occurring over longer time scales. Here, we use a long-term data set (1974-2009, 35 years) of tree stems ( $>3$ $\mathrm{cm}$ in diameter at $1.3 \mathrm{~m}$ aboveground) in four sites ( 0.35 ha in total) in montane rain forest $(\sim 1600 \mathrm{~m}$ elevation) in Jamaica to investigate the patterns of crown damage in individual stems by Hurricane Gilbert in 1988, and how subsequent growth and mortality were affected by hurricane damage, sprouting, and the incidence of multiple stems. Topographical position on a mountain ridge was the best predictor of crown damage, followed by crown size and species identity. The average diameter growth rate of stems that survived the hurricane was greater than that pre-hurricane for the whole 21-yr post-hurricane period. Growth rates of stems with damaged crowns increased less than those with undamaged crowns; differences in growth rate between damaged and undamaged trees disappeared after 11 years. Hurricanedamaged stems had two to eight times higher mortality than undamaged stems for 19 years post hurricane. Many stems sprouted shortly after the hurricane, but few sprouts managed to establish (grow to $>3 \mathrm{~cm}$ diameter at breast height). However, sprouting and multi-stemming were associated with reduced mortality rate, particularly in damaged trees. From an initial population of 1670 stems in 1974, 54\% were still alive in 2009 (21 years after the hurricane). We conclude that despite the high frequency of hurricane damage to tree crowns and the subsequent increased mortality rate in this hurricane-prone tropical montane forest, many stems will be hit and recover from several hurricanes in their lifetime.
\end{abstract}

Key words: Bayesian; Caribbean; cyclone; defoliation; demography; disturbance; forest dynamics; forest structure; mortality; multiple stems; sprouting; tree growth.

\section{INTRODUCTION}

Natural disturbances such as fires and hurricanes can have major impacts on forests' structure and dynamics despite their short duration (from hours to a few days; Overpeck et al. 1990, Foster et al. 1998). Wind storms can damage large numbers of trees (Coutts and Grace 1995, Vandermeer et al. 2000), affecting subsequent tree demography, forest dynamics, and ecosystem processes (Foster and Boose 1995, Foster et al. 1998). The effects of tropical cyclones are particularly strong (Zimmerman et al. 1996, Lugo 2008), and their intensity (wind speed and amount of rainfall) is expected to increase in the coming decades due to climate change (Field et al. 2012). Despite the importance of these effects, only a few studies have assessed the long-term (more than a decade)

Manuscript received 24 September 2013; revised 24 February 2014; accepted 27 February 2014. Corresponding Editor: A. W. D'Amato.

4 E-mail: evt1@cam.ac.uk

${ }^{5}$ Present address: Department of Integrative Ecology, Estación Biológica de Doñana, CSIC, Avenida Américo Vespucio S/N, Sevilla E-41092 Spain. consequences of wind damage on the growth of individual trees (e.g., Merrens and Peart 1992, Busby et al. 2008), and fewer still have addressed consequences on tree mortality (e.g., Weaver 1986, Burslem et al. 2000). Most studies are done within a few years of the impact of a cyclone (called hurricanes in the Atlantic), and describe the form of damage and differences between species in damage and mortality (e.g., in Jamaica, Bellingham et al. [1995]; in Puerto Rico, USA, Ostertag et al. [2005]; see Everham and Brokaw [1996] and Lugo [2008] for general reviews). These shortterm studies may miss tree and forest responses occurring over longer time scales, and quite often lack pre-hurricane data to serve as a baseline for comparison of post-hurricane dynamics.

The scarcity of long-term studies results in high uncertainties regarding the magnitude and duration of hurricane impacts on tree mortality and growth. In lower montane rain forest in Puerto Rico, mortality rates increased and growth rates were lower in hurricane-damaged stems than in undamaged stems for about four years after a major hurricane (Uriarte et al. 2004, 2012). In Florida, over seven years after Hurricane 
Kate, growth and mortality rates were higher or lower than pre-hurricane rates, depending on the tree species (Batista and Platt 2003). In the Solomon Islands, recruitment and mortality rates were still higher 24-28 years after cyclones struck (Burslem et al. 2000). In New Hampshire, tree growth was higher in a hurricanedamaged stand than in a comparatively undamaged stand, for two of four species for 44-48 years after a hurricane (Merrens and Peart 1992). In South Carolina, previously damaged trees were more likely to be damaged by a subsequent hurricane (Putz and Sharitz 1991). These studies establish that hurricane effects on tree mortality and growth can be long-lasting, but also highly variable. The factors driving the apparent variation in the magnitude, species-specificity, and duration of hurricane impacts remain unclear.

In Jamaica, our studies of forest dynamics in permanent plots in the Blue Mountains have already shown that mortality and growth increased shortly after a hurricane impact (Bellingham et al. 1995), and that species composition changed over the 20-yr period 1984-2004 (with Hurricane Gilbert in 1988), with an increase in rarer species and recruitment of lightdemanding species formerly absent from the plots (Tanner and Bellingham 2006). In this study we exploit this long-term (14 years pre-hurricane and 21 years posthurricane) tropical forest data set to address the following questions: what factors were associated with hurricane damage to tree crowns? What was the magnitude and duration of hurricane-caused damage on stem growth and mortality? Was tree sprouting after the hurricane and possession of multiple stems associated with long-term survival of trees post-hurricane?

\section{Methods}

We report analyses of data from before and after Hurricane Gilbert, the eye of which passed less than 10 $\mathrm{km}$ south of our study sites on 12 September 1988. Hurricane Gilbert had the lowest atmospheric pressure yet recorded for a North Atlantic cyclone: its wind speeds were up to $194 \mathrm{~km} / \mathrm{h}$ as it crossed Jamaica (Lawrence and Gross 1989). In the subsequent 21 years of our study, no hurricane eye passed over (eastern) Jamaica, although there were several near misses in the period 2004-2009. These near misses did not have strong effects on the natural forest as judged by the fact that no stems of the very light-demanding but shortlived species Bocconia frutescens were observed in the forest in the vicinity of the study sites in 2009 , whereas for at least five years after Hurricane Gilbert in 1988, stems of this small tree were widespread. In the 37 years between Hurricanes Charlie in 1951 and Gilbert in 1988, no other hurricane eye passed within $50 \mathrm{~km}$ of the study sites. We conclude that the effects we are studying are predominantly attributable to Hurricane Gilbert in 1988 and not those of earlier or more recent but more distant hurricanes.
Our study sites are in forests that are on and near the main ridge of the Blue Mountains of Jamaica $\left(18^{\circ} 05^{\prime} \mathrm{N}\right.$, $76^{\circ} 39^{\prime} \mathrm{W}, 1500-1650 \mathrm{~m}$ altitude). We had four sites (Col [0.09 ha], Mor [0.06 ha], Mull [0.1 ha], and Slope [0.1 ha]); each site was composed of $6-10$ contiguous $10 \times 10$ $\mathrm{m}$ plots (Appendix A; further details in Tanner [1977], Tanner and Bellingham [2006]). The Mull, Col, and Mor sites are on the crest of an undulating steep-sided main ridge that runs approximately southeast to northwest. The slope to the northeast of the Mull site is $42^{\circ}$, and to the southwest of it is $33^{\circ}$. The main ridge rises by $60 \mathrm{~m}$ over a horizontal distance of $150 \mathrm{~m}$ from the southeast to the Mull site, and then falls by about $15 \mathrm{~m}$ to the northwest into a gap in the main ridge where the Col site is situated; it then rises by about $30 \mathrm{~m}$ to a knoll where the Mor site is situated (Appendix A). The Slope site is 15-50 $\mathrm{m}$ down the northern side of the main ridge. The hurricane came in from the southeast and the eye passed overland to the south of the main ridge. Thus the Mull site was most exposed, the Mor next most exposed, and the Col was relatively protected by the $15 \mathrm{~m}$ decrease in altitude from the Mull to the $\mathrm{Col}$ (and the $30 \mathrm{~m}$ rise in altitude from the $\mathrm{Col}$ to the Mor) and its position $\sim 150$ $\mathrm{m}$ back from the top of the slope leading up to the Mull. The Slope site was the least exposed, because of its position on the northern slopes, which were relatively protected from the eye of Hurricane Gilbert (Bellingham 1991).

The stems were measured in 1974, 1984, 1989, 1991, 1994, 2004, and 2009. At each census, all stems with diameter at breast height (dbh, $1.3 \mathrm{~m}$ aboveground) $>3$ $\mathrm{cm}$ were scored as live or dead, identified to species, and measured on a painted band (see Appendix B for descriptive statistics of the number of stems, species, and stem size for each site). Stems part of multi-stemmed individuals were recorded as separate stems and their connection recorded. In the first re-enumeration after Hurricane Gilbert (1989), crowns of living trees were scored for damage using a four-point qualitative scale: (1) crown detached (crowns broken off but with epicormic sprouts developing), (2) crown bare (no leaves, i.e., completely defoliated), (3) crown sparse (few leaves), or (4) crown undamaged; herein we amalgamated the three categories 1,2 , and 3 into a category of "damaged" to be compared with undamaged. For 703 stems with smaller diameter crowns (stem dbh $7.2 \pm 0.1 \mathrm{~cm}[$ mean $\pm \mathrm{SE}]$ ), the crowns were scored as a whole; for 622 stems with larger diameter crowns (stem dbh $15.6 \pm 0.3 \mathrm{~cm}$ ), the crowns were divided into upper and lower portions, which were scored separately; we used only data from the upper portion. Species names follow Adams (1972), updated and with other authorities (Appendix C, see also sources available online ${ }^{6}{ }^{6}$

\footnotetext{
${ }^{6} \mathrm{http}: / /$ www.theplantlist.org/
} 
We used hierarchical Bayesian modeling to estimate the effects of spatial location (site, plot) and individual characteristics (species, crown size [large or small], and previous diameter growth rate [an indicator of tree vitality]) on the probability of crown damage (damaged cf. undamaged) by the hurricane ( $n=1259$ stems from 48 species, excluding dead trees and tree ferns). Specifically, for every individual stem $i$ of species $j$ growing in plot $l$ at site $k$, the probability of being damaged $\left(\varphi_{i j k l}\right)$ was modeled as

$$
\begin{aligned}
\operatorname{logit}\left(\varphi_{i j k l}\right)= & \alpha_{k}+\gamma_{l}+\delta_{j}+\beta_{1} \times \text { crown size }_{i} \\
& +\beta_{2} \times{\text { growth } \text { rate }_{i}}
\end{aligned}
$$

where crown size was a binary variable (either large or small) and growth rate represents the average stemgrowth rate during the period 1974-1984 (pre-hurricane). We used relatively non-informative priors for all parameters. Parameters $\beta_{1}$ and $\beta_{2}$ had normal priors with mean 0 and a large standard deviation (1000). In this and all subsequent analyses, site effects $\left(\alpha_{k}, k=1\right.$, $\ldots, 4)$ were modeled as fixed effects $\alpha_{k} \sim \operatorname{Normal}(0$, 1000), while plot $\left(\gamma_{l}\right)$ and species $\left(\delta_{j}\right)$ effects were modeled hierarchically as $\gamma_{l} \sim \operatorname{Normal}\left(0, \sigma_{\text {plot }}\right)$ and $\delta_{j}$ $\sim \operatorname{Normal}\left(0, \sigma_{\mathrm{spp}}\right)$. Both standard deviations $\sigma_{\text {plot }}$ and $\sigma_{\text {spp }}$ had flat priors Uniform $(0,10)$.

Stem-diameter growth rates over time were modeled as a function of location (site, plot), species, individual, and damage score. For this analysis, we only included stems surviving the whole study period $(n=915$ stems from 41 species). Specifically, the average diameter growth rate $G$ of a stem $i$ of species $j$ growing in plot $l$ at site $k$ during census $t(t=1,2, \ldots, 6)$ was modeled as

$$
G_{i j k l t} \sim \operatorname{Normal}\left(g_{i j k l t}, \sigma_{G}\right)
$$

where

$$
g_{i j k l t}=\alpha_{k}+\gamma_{l}+\delta_{j}+\theta_{i}+\beta_{t}+\omega_{t} \times \text { Damage }_{i} .
$$

Damage is a binary variable separating hurricanedamaged from undamaged trees. The variable $\omega_{t}$ was given a standard non-informative prior, $\omega_{t} \sim \operatorname{Normal}(0$, 1000). Site $\left(\alpha_{k}\right)$, plot $\left(\gamma_{l}\right)$, and species $\left(\delta_{j}\right)$ effects were modeled as above. We accounted for individual variation in growth rates by including random individual effects $\theta_{i} \sim$ Normal $\left(0, \sigma_{l}\right)$, with inter-individual standard deviation $\sigma_{l}$ having flat prior Uniform $(0,10)$, as well as the residual standard deviation $\sigma_{G}$.

We modeled stem mortality as a Bernouilli process, accounting for the different duration of census intervals (Ogle et al. 2006). The probability of mortality of any stem during census $t\left(\tau_{i t}\right)$ was equal to $1-\left(1-M_{i t}\right)^{Y t}$, where $M_{i t}$ is the annual probability of mortality of stem $i$ during census $t$, and $Y_{t}$ is the number of years spanning the census (Lines et al. 2010). The annual probability of mortality of any stem was subsequently modeled for each census taking into account its location, species identity, and damage status

$$
\operatorname{logit}\left(M_{i j k l}\right)=\alpha_{k}+\gamma_{l}+\delta_{j}+\beta_{D} \times \text { Damage }_{i} .
$$

We modeled site, plot, and species effects $\left(\alpha_{k}+\gamma_{l}+\delta_{j}\right.$, respectively) in the same way, and the effects of damage on mortality were given a standard non-informative prior: $\beta_{D} \sim \operatorname{Normal}(0,1000)$.

Many stems sprouted in response to hurricane damage. We analyzed the variation in sprouting frequency among stems, plots, and species, and the subsequent effects of sprouting on post-hurricane mortality. In the 1989 census, one year after the hurricane, we recorded the stems that had sprouted from the crown base (above $2.5 \mathrm{~m}$ high). The probability of sprouting was then modeled as a function of stem location (site, plot), species, damage score (damaged or not), and crown size (large or small) using the logit link. Subsequently, we assessed whether crown sprouting and being multi-stemmed had any influence on overall posthurricane mortality (1989-2009) by repeating the mortality analysis above for individual trees $(n=$ 1390), this time including parameters accounting for sprouting, multi-stemming, and their interaction.

As we aim to explain tree responses to hurricane damage in these particular sites rather than extrapolating to other forests, we report finite-population standard deviations throughout (Gelman and Hill 2007). All analyses were run in R 3.0 (R Development Core Team 2013) and JAGS 3.3.0 (Plummer 2003) by means of the R2jags package (Su and Yajima 2012).

\section{RESUlTS \\ Crown damage}

Hurricane Gilbert caused extensive crown damage: 58 months after the hurricane, of the 622 stems with larger crowns scored for damage, $38 \%$ were undamaged, $28 \%$ sparsely foliated, $18 \%$ bare, and $16 \%$ crown detached. Of the 703 stems with smaller crowns, $66 \%$ were undamaged, $22 \%$ sparsely foliated, $5 \%$ bare, and $7 \%$ crown detached. The best predictor of whether a crown was damaged was topographical position. Trees in the most affected (Mull) site, on a convex ridge top, had a $37 \%$ greater probability of crown damage on average than trees in the least affected, north-facing, Slope site (Table 1, Fig. 1). The next most important predictors were crown size and species; having a large crown increased damage probabilities by $26 \%$ (calculated from values in Table 1), and belonging to the most susceptible species (Solanum punctulatum) increased the probability of damage by $47 \%$ compared with the least susceptible species (Podocarpus urbanii; Appendix C). However, we did not detect strong differences in susceptibility to damage among most species: only three species had estimated susceptibility significantly different from zero, and mean effect size lay between + and -0.5 (logit scale) for 38 out of 48 species, including some that were relatively abundant (Appendix C). Finally, pre-hurricane growth rates only had a small effect on the likelihood that a stem was damaged, as a $1 \mathrm{~mm} / \mathrm{yr}$ higher 
TABLE 1. Estimated effects of location (site and plot), species identity, crown size, and prehurricane growth rate (1974-1984) on the probability of damage by the hurricane (recorded in 1989), for 1259 stems of 48 species (tree ferns were excluded) that were alive in 1974, 1984, and 1989.

\begin{tabular}{|c|c|c|c|c|}
\hline \multirow[b]{2}{*}{ Factor } & \multirow[b]{2}{*}{ Mean } & \multirow[b]{2}{*}{ SE } & \multicolumn{2}{|c|}{ Credible interval } \\
\hline & & & $2.5 \%$ & $97.5 \%$ \\
\hline $\mathrm{Col}$ & -1.10 & 0.30 & -1.70 & -0.52 \\
\hline Mor & -0.25 & 0.30 & -0.83 & 0.37 \\
\hline Mull & 0.45 & 0.26 & -0.06 & 0.95 \\
\hline Slope & -1.43 & 0.27 & -1.99 & -0.91 \\
\hline Large crown & 1.28 & 0.15 & 1.00 & 1.57 \\
\hline Pre-hurricane growth rate $(\mathrm{cm} / \mathrm{yr})$ & -4.12 & 0.97 & -6.02 & -2.26 \\
\hline \multicolumn{5}{|l|}{ Random effects } \\
\hline Species & 0.68 & 0.12 & 0.47 & 0.93 \\
\hline Plot & 0.46 & 0.09 & 0.29 & 0.65 \\
\hline
\end{tabular}

Notes: Mean effect size, standard error, and $2.5 \%$ and $97.5 \%$ credible intervals are shown (logit scale); positive mean values indicate higher probability of damage compared to small-crowned stems with zero net growth pre-hurricane, which were used as the baseline. Col, Mor, Mull, and Slope all represent study sites in the Blue Mountains of Jamaica, see Appendix A for more detail. Values presented for random effects correspond to standard deviations.

growth rate (a big difference given that the average growth rate of all stems alive throughout the study period was $0.6 \pm 0.02 \mathrm{~mm} / \mathrm{yr}$ ) translated into only an $8 \%$ decrease in the overall probability of damage (Table 1 , Fig. 1).

\section{Stem growth and mortality}

The average stem-diameter growth rate of surviving stems over the full 21-yr post-hurricane period was greater than that pre-hurricane (Fig. 2, Appendix D). Whereas growth rates of damaged stems were quite stable over the whole post-hurricane period, undamaged stems showed a fourfold increase immediately after the hurricane, declining to the same level as damaged trees by 11 years after the hurricane (Fig. 2). Average diameter growth rates of damaged and undamaged stems 1-3 years after the hurricane (1989-1991) were $77 \%$ and $160 \%$ higher, respectively, than before the

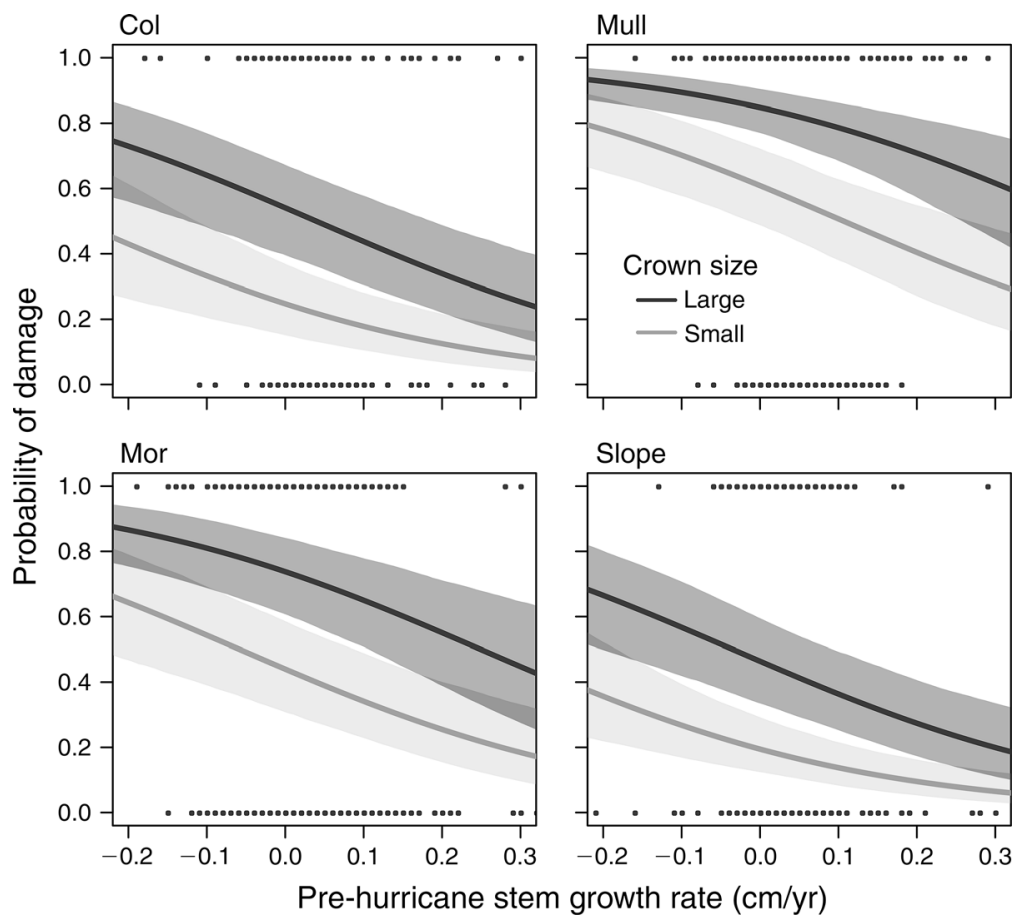

FIG. 1. Probability of hurricane damage according to stem location (four sites: Col, Mor, Mull, and Slope, all in or near the Blue Mountains of Jamaica; see Appendix A for more detail), crown size (large or small), and pre-hurricane (1974-1984) diameter growth rate $(n=1259$ stems). Shaded areas represent $95 \%$ credible intervals. Dots represent observed growth rates for damaged (top of graph) and undamaged (bottom of graph) trees. 


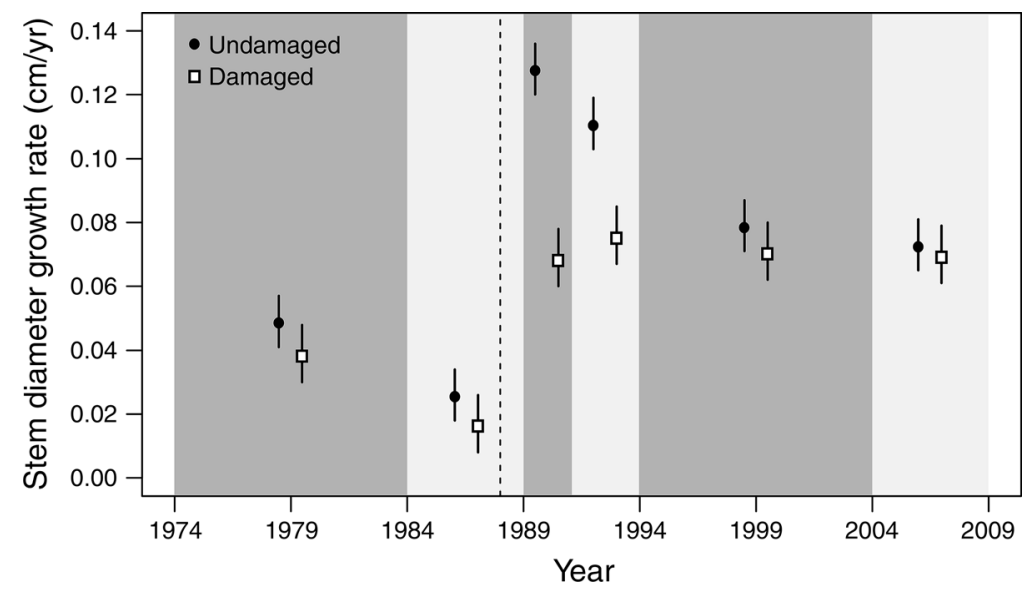

FIG. 2. Stem diameter growth rates (mean $\pm \mathrm{SE}$ ) prior to and following Hurricane Gilbert for crown-damaged and crownundamaged stems. The dashed line marks the year of the hurricane (1988). Shaded background represents the time span of each census; parameter estimates are plotted in the middle of the census period. Only stems surviving the whole period (1974-2009) were included in this analysis $(n=915$ stems $)$.

hurricane (1974-1984). The diameter growth rate of damaged stems was significantly lower than that of undamaged stems for up to six years post-hurricane (1989-1991 and 1991-1994; Fig. 2). There was also substantial variation among species and individuals within species (Appendix D): although surviving trees of all species responded positively to the hurricane in terms of subsequent growth rate, the increase was much greater in some species (e.g., Alchornea latifolia) than others (Lyonia octandra; Appendix E).

Overall stem mortality rates (damaged and undamaged stems together) were higher in the six years after the hurricane and slowly returned to pre-hurricane rates 6-21 years post-hurricane (Fig. 3). The increase was entirely attributable to the significantly greater mortality rates of stems with hurricane-damaged crowns (3.4\% per year, 1989-1994) vs. stems with undamaged crowns (0.45\% per year, 1989-1994). During the same 6-yr period, the probability of mortality of stems with undamaged crowns was less than half that of the prehurricane years. Hurricane effects on mortality were long-lasting: stems with damaged crowns had significantly greater mortality than undamaged stems for between 16 and 21 year post-hurricane (Fig. 3). At the time of the last census (2009), mortality rates of stems with damaged and undamaged crowns had still not fully converged. Hurricane damage thus had longer-term effects on mortality than on growth; differences in stemdiameter growth between damaged and undamaged trees mostly disappeared between 6 and 16 year after the hurricane (Fig. 2).

\section{Sprouting}

Sprouts above $2.5 \mathrm{~m}$ on a stem were present on $38 \%$ of stems in 1989, a year after the hurricane. The presence of sprouts was very species-dependent, including frequent

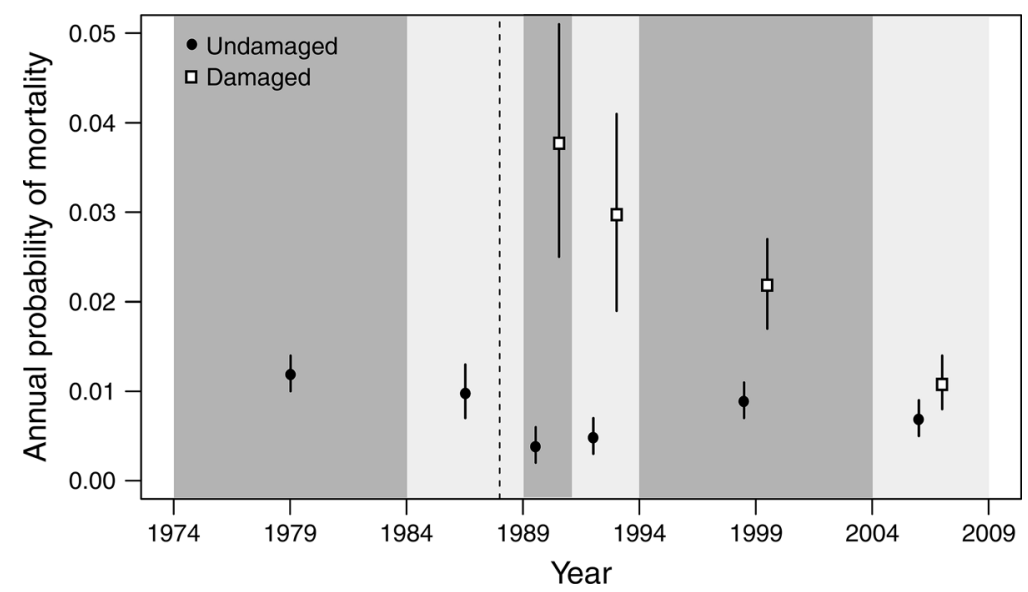

FIG. 3. Effects of hurricane damage on stem mortality (mean \pm SE) across the whole study period. The dashed line marks the year of the hurricane (1988). Shaded background represents the time span of each census; parameter estimates are plotted in the middle of the census period. 
TABLE 2. Effects of stem location (site and plot), species, crown size, and damage status on the probability of sprouting after the hurricane ( $n=1670$ stems from 63 species).

\begin{tabular}{lccrr}
\hline \hline & & & \multicolumn{2}{c}{ Credible interval } \\
\cline { 4 - 5 } \multicolumn{1}{c}{ Factor } & Mean & SE & $2.5 \%$ & $97.5 \%$ \\
\hline Col & -1.99 & 0.39 & -2.77 & -1.25 \\
Mor & -0.64 & 0.40 & -1.43 & 0.14 \\
Mull & -1.47 & 0.35 & -2.16 & -0.81 \\
Slope & -1.89 & 0.36 & -2.60 & -1.19 \\
Undamaged and large crown & 0.78 & 0.20 & 0.39 & 1.17 \\
Damaged and small crown & 0.43 & 0.18 & 0.07 & 0.79 \\
Damaged and large crown & 0.40 & 0.18 & 0.05 & \\
Random effects & & & & 2.00 \\
$\quad$ Species & 1.48 & 0.23 & 0.11 & 0.85 \\
Plot & 0.62 & 0.11 & 0.43 & \\
\hline
\end{tabular}

Notes: Mean effect size, standard error, and 2.5\% and $97.5 \%$ credible intervals are shown (logit scale); positive mean values indicate more sprouting compared to undamaged, small-crowned stems used as baseline. Values presented for random effects correspond to standard deviations.

sprouters (e.g., Eugenia biflora, Lyonia octandra, Chaetocarpus globosus, and Sideroxylon montanum) and nonsprouters (Clusia havetioides and Schefflera sciodaphyllum). On average, large-crowned undamaged trees showed the highest probability of sprouting (33\%; Table $2)$. Damaged stems showed slightly lower sprouting $(\sim 25 \%)$ regardless of their crown size. Despite the intense post-hurricane sprouting (both above and below $2.5 \mathrm{~m}$ on a stem), the percentage of multiple-stemmed individuals hardly changed throughout the 35 -yr period, from $13.0 \%$ in 1974 to $13.5 \%$ in $1989,14.1 \%$ in 1994 , $14.6 \%$ in 2004 , and $13.9 \%$ in 2009 . Sprouting and having multiple stems (which were correlated) were associated with lower long-term (1989-2009) mortality in damaged trees (average mortality rate around 2.3\% per year compared to $3.5 \%$ for damaged single-stem, nonsprouted trees). Sprouting and multi-stemming effects on mortality were apparently much weaker for undamaged trees; the significant effect for undamaged sprouted multi-stems (Table 3 ) has a wide credible interval and is based on only 23 stems. There were 365 recruits to the plots in years one to six after the hurricane (1989-1994); $34 \%$ of these were part of a multi-stemmed individual, not significantly different from the $30 \%$ of 121 stems recruited between 1984 and 1989 (four years before and the first year immediately after the hurricane, respectively). Thus, stem recruitment after the hurricane derived mostly from sexual regeneration (i.e., seeds or

TABLE 3. Effects of tree location (site and plot), species, hurricane damage, sprouting, and multistemming on the long-term probability of mortality of individual trees $(1989-2009 ; n=1390$ trees).

\begin{tabular}{|c|c|c|c|c|}
\hline \multirow[b]{2}{*}{ Factor } & \multirow[b]{2}{*}{ Mean } & \multirow[b]{2}{*}{ SE } & \multicolumn{2}{|c|}{ Credible interval } \\
\hline & & & $2.5 \%$ & $97.5 \%$ \\
\hline $\begin{array}{l}\text { Col } \\
\text { Mor } \\
\text { Mull } \\
\text { Slope }\end{array}$ & $\begin{array}{l}-4.28 \\
-4.52 \\
-4.32 \\
-4.83\end{array}$ & $\begin{array}{l}0.22 \\
0.27 \\
0.22 \\
0.22\end{array}$ & $\begin{array}{l}-4.72 \\
-5.05 \\
-4.74 \\
-5.27\end{array}$ & $\begin{array}{l}-3.84 \\
-4.00 \\
-3.89 \\
-4.39\end{array}$ \\
\hline \multicolumn{5}{|l|}{ Undamaged } \\
\hline $\begin{array}{l}\text { Sprouted (single stem) } \\
\text { Multi-stem (not sprouted) } \\
\text { Sprouted multi-stem }\end{array}$ & $\begin{array}{l}-0.32 \\
-0.20 \\
-2.14\end{array}$ & $\begin{array}{l}0.23 \\
0.46 \\
1.29\end{array}$ & $\begin{array}{l}-0.78 \\
-1.17 \\
-5.29\end{array}$ & $\begin{array}{r}0.13 \\
0.60 \\
-0.24\end{array}$ \\
\hline \multicolumn{5}{|l|}{ Damaged } \\
\hline $\begin{array}{l}\text { Single stem, not sprouted } \\
\text { Sprouted (single stem) } \\
\text { Multi-stem (not sprouted) } \\
\text { Sprouted multi-stem }\end{array}$ & $\begin{array}{l}1.17 \\
0.72 \\
0.74 \\
0.10\end{array}$ & $\begin{array}{l}0.15 \\
0.20 \\
0.28 \\
0.29\end{array}$ & $\begin{array}{r}0.87 \\
0.34 \\
0.16 \\
-0.49\end{array}$ & $\begin{array}{l}1.47 \\
1.11 \\
1.28 \\
0.62\end{array}$ \\
\hline \multicolumn{5}{|l|}{ Random effects } \\
\hline $\begin{array}{l}\text { Species } \\
\text { Plot }\end{array}$ & $\begin{array}{l}0.90 \\
0.17\end{array}$ & $\begin{array}{l}0.12 \\
0.09\end{array}$ & $\begin{array}{l}0.67 \\
0.01\end{array}$ & $\begin{array}{l}1.15 \\
0.34\end{array}$ \\
\hline
\end{tabular}

Notes: Mean effect size, standard error, and $2.5 \%$ and $97.5 \%$ credible intervals are shown (logit scale); positive mean values indicate higher probability of mortality compared to undamaged, single, non-sprouted stems used as baseline. Values presented for random effects correspond to standard deviations. 
seedling bank) rather than basal sprouting of older individuals.

\section{Discussion}

\section{Hurricane damage: its correlates and its effects on stem growth and mortality}

Crown damage caused by Hurricane Gilbert was related to topographic position, crown size, and species identity. Our results show that topographic position and the degree of exposure to strong winds are important predictors of damage in sites along a mountain ridge (see also Boose et al. 1994, 2004) and can override other factors (e.g., tree size, species identity) that are often emphasized in the literature on hurricane impacts (Everham and Brokaw 1996). In highly exposed stands, most trees will experience greater damage regardless of their individual characteristics, and vice versa: protected stands will act as refugia where both less susceptible and more susceptible trees will be more likely to escape hurricane damage. Topographical effects, when investigated, have sometimes given apparently contradictory results. For example, after different hurricanes affected forests in the Luquillo Mountains in Puerto Rico, Ostertag et al. (2005) reported that trees growing on ridges and valleys were more affected than those on slopes, whereas Scatena and Lugo (1995) found that trees on slopes were more affected than those on ridges; possibly because the root-grafted Dacryodes excelsa was particularly abundant on ridges in that area (Lugo 2008). Another study in a 16-ha plot in the Luquillo Mountains found that topographical effects were of lesser importance than tree size and species identity in determining crown damage caused by Hurricane Hugo (Canham et al. 2010). Therefore, the probability of hurricane damage seems to be determined by the interplay of landscape position and individual tree characteristics (e.g., large trees were more affected). These interactions between intrinsic (individual) and extrinsic (landscape) factors should be considered more thoroughly in future studies assessing patterns of hurricane damage in forests.

The average stem-diameter growth rate (all stems damaged and undamaged) was greater for the full 21-yr post-hurricane period than in the pre-hurricane period. The growth of stems with hurricane-damaged crowns increased less than those with undamaged crowns; this difference persisted for 11 years after the hurricane hit. The increased stem growth rate after the hurricane was probably due to increased light reaching the middle and lower levels of the canopy (Bellingham et al. 1996, Tanner and Bellingham 2006) and reduced belowground competition, caused by the severe damage to many large crowns; similar patterns have been found elsewhere (Lugo 2008). In Puerto Rican rain forests affected by Hurricane Hugo, the diameter growth of undamaged stems exceeded that of damaged for six of 12 dominant tree species for four years post-hurricane (Uriarte et al. 2004), in a general context of increased forest growth rates (e.g., net primary productivity in nearby forests tripled after two hurricanes; Lugo 2008). Other studies found longer-lasting increases of tree growth posthurricane, e.g., at least seven years in Florida (Batista and Platt 2003), a decade in the Dominican Republic (Sherman et al. 2012), and $>40$ years in New Hampshire (Merrens and Peart 1992). Hence, even though increased growth of surviving trees after a hurricane, especially those less damaged, seems to be a general phenomenon, there is considerable variation in the duration and magnitude of growth stimulation among species and forest types. These could be explained by differences in forest structure, damage intensity, species resilience, and post-disturbance recovery strategies, and speed of canopy closure after the hurricane (Lugo 2008). Our results confirm that, even within the same forest, posthurricane growth rates will vary substantially between species and trees within species depending on the amount of damage (Fig. 2, Appendices D and E). Hence, studies based on short-term time series (e.g., lacking evaluation of damage immediately after the hurricane, or pre-hurricane growth data) and focused on stand rather than individual scales (e.g., analyzing changes in total basal area rather than individual stems' demography) may miss more subtle yet important longterm consequences of hurricane disturbances on forest dynamics.

Higher tree mortality rates after hurricanes have often been documented (Everham and Brokaw 1996), though the duration of that increase is rarely reported. In the Jamaican forest in this study, mortality of damaged stems was higher for $\sim 19$ years after a severe hurricane. In forests of the Luquillo Mountains in Puerto Rico, Hurricane Hugo caused increased tree mortality over about four years (Uriarte et al. 2004), but this effect was not evident by a third census 11-12 years after the hurricane (Uriarte et al. 2012). Despite the increased mortality post-hurricane, many trees are likely to survive several hurricanes; in Jamaica, $54 \%$ of the initial population of 1670 stems in 1974, $71 \%$ of all stems present in 1984 (before Hurricane Gilbert), and 59\% of those damaged by the hurricane were still alive by 2009 . Average annual mortality rates in the 21 years posthurricane were $0.5 \%$ higher $(1.6 \%)$ than pre-hurricane baselines (1.1\%). Thus, although return times of hurricanes to the Jamaican Blue Mountains are very irregular, given that the average is $\sim 25$ years (five hurricane eyes passed within $20 \mathrm{~km}$ of the Blue Mountains between 1870 and 2010), most stems will experience more than one hurricane in their lifetime. This seems to be true in other forests, too; in Puerto Rico, $26 \%$ of stems $>4.1 \mathrm{~cm}$ dbh survived from 1946 to 2000 (Weaver 2002), a period that included hurricanes in 1956, 1989, and 1998.

\section{Role of sprouting in post-hurricane recovery}

After a hurricane, epicormic sprouting on tree trunks is obvious (Yih et al. [1991] in Nicaragua; Bellingham et 
al. [1994] in Jamaica; Zimmerman et al. [1994] in Puerto Rico). Sprouting is an efficient means of mobilizing stored reserves to regain lost biomass and leaf area (Sakai and Sakai 1998). Hurricanes often cause widespread defoliation, and sprouts may help maintain photosynthesis in the years immediately after the hurricane while the stems regrow their main canopy. In Puerto Rican rain forests affected by Hurricane Hugo, Walker (1991) asserted that widespread sprouting and minimal breakage of large branches would result in tree recovery despite that fact that $56 \%$ of trees were defoliated, and Boucher (1990) made similar predictions about Nicaraguan rain forests affected by Hurricane Joan. In our study, sprouting was positively related to survivorship: stems with hurricane-damaged crowns that sprouted above $2.5 \mathrm{~m}$ height had much lower mortality (2.3\% per year over the 21-yr post-hurricane period) than non-sprouted stems $(3.5 \%)$. Some sprouts from below $1.3 \mathrm{~m}$ survived and grew large enough to be included in stem censuses $(\geq 3.0 \mathrm{~cm} \mathrm{dbh})$, but two-thirds of the newly recruited stems five years after the hurricane originated from seedlings, not sprouts from existing tree stems. The importance of sprouting for post-disturbance recovery is, however, strongly speciesspecific (Table 2; Dietze and Clark 2008, Uriarte et al. 2012). Beyond new stem recruitment, basal sprouts contribute to multi-stemmed individuals having a greater chance of survival than single-stemmed individuals, in Jamaica (Bellingham and Sparrow 2009), Samoa (Webb et al. 2014), and probably Puerto Rico (Uriarte et al. 2012). However, experimental removal of basal sprouts will be necessary to establish if sprouting causes increased survival or if it is simply that more vigorous individuals have both more sprouts and higher survival.

\section{Long-term effects of hurricanes at the stand level}

In Jamaica, stems comprising $32 \%$ of the total basal area present in 1974 had died by 2004 (Tanner and Bellingham 2006). However, total basal area per plot remained very similar, due to the increased growth of survivors (Fig. 2) and the increased post-hurricane recruitment (Tanner and Bellingham 2006) that compensated for the basal area mortality. Results from several other countries also show that the total stand basal area can remain quite stable or recover quickly after major wind damage (Lugo 2008), though there are often other changes such as shifts in species composition (Bellingham et al. 1995) or stand structure, including shifts to more and smaller stems (Merrens and Peart 1992, Bellingham et al. 1995). Such changes can happen slowly, even in the course of several centuries (Foster et al. 1998, Lugo 2008). The disturbance regime is likely to govern responses. We have shown that, in Jamaica, where the average return interval for hurricanes is 25 years, a single hurricane increased overall growth for the whole 21-yr post-hurricane period, and hurricanedamaged stems had reduced growth for 11 years and increased mortality for 19 years. However, some forests are subject to several powerful cyclonic storms within a decade; for example, in northeastern Australia (Webb 1958), Taiwan (Lin et al. 2011), and the northeastern USA (Papaik and Canham 2006). The consequences of damage to individual stems in these "hyper-disturbed" forests have not been determined. The species composition of forests and the traits of individual species, including their susceptibility to pathogens, are likely to determine responses to repeated disturbances. In species-rich forests, differential damage among species (Canham et al. 2010) can result in long-term differences in growth among species (Appendix E). This in turn can lead to compositional shifts along a continuum of resilient to resistant species (Bellingham et al. 1995, Batista and Platt 2003; see also Wonkka et al. 2013), which is likely to be related to time since disturbance (Holling 1973). Finally the high variability in frequency of hurricane impacts at any location (Healey 1990, Sherman et al. 2012) will further complicate these effects. Thus, the interaction of disturbance regimes and species differential responses generate complex and varied patterns of forest dynamics (Papaik and Canham 2006).

\section{Conclusion}

Long-term monitoring of forest plots can provide important insights on the effects of hurricanes and other natural disturbances on tree demography and forest stand dynamics. The availability of pre-hurricane data enabled us, for instance, to detect a significant overall increase of stem growth rates following the hurricane. In the absence of pre-hurricane baseline data, hurricaneinduced changes in tree demography would remain undetected or, even worse, misinterpreted. Furthermore, the demographic impacts of hurricane damage can be long-lasting; in Jamaica, 19 years for mortality and 11 years for growth. In forests where there is a lot of topographic diversity (as in Jamaica), position in the landscape is a strong determinant of hurricane damage, after which crown size and tree species are the next most important correlates. Recovery from damage was higher in multiple-stemmed trees and stems with sprouts above $2.5 \mathrm{~m}$. Some basic aspects of forest structure are often not greatly affected by hurricanes, for example, total basal area. Other aspects of structure, like canopy height and crown diameters, are likely to be more affected by hurricanes but are rarely recorded before hurricanes (a notable exception is the study of Wunderle et al. 1992).

Despite the high frequency of damage to tree crowns and associated increased mortality rate, most stems survived long after the hurricane. Given the high frequency of hurricanes and windstorms in many tropical areas, it is likely that many canopy trees will be damaged and recover from several severe disturbances in their lifetime.

\section{ACKNOWLedgments}

E. V. J. Tanner, P. J. Bellingham, and J. R. Healey conceived the research and collected the data (the latter aided by various 
field assistants acknowledged in earlier papers). E. V. J. Tanner, R. J. Holdaway, and especially F. Rodriguez-Sanchez analyzed the data. E. V. J. Tanner, F. Rodriguez-Sanchez, and P. J. Bellingham wrote the paper, other authors made critical revisions to the paper. Thanks are due to the following authorities in Jamaica: (1) the Heads of the Department of Forestry in the Ministry of Agriculture, and the park managers of the Blue Mountains and John Crow Mountains National Park for permission to undertake the study; (2) the directors of the Botanic Gardens Division of the Ministry of Agriculture for permission to use the Cinchona Botanic Gardens as a field station; (3) G. H. Sidrak, L. B. Coke, P. V. Devi Prasad, R. Robinson, D. Webber. E. Hyslop, M. Webber, J. Cohen, and K. McLaren of the Department of Botany (more recently Life Sciences) of the University of the West Indies for assistance and facilities. F. Rodriguez-Sanchez was supported by the European Union Seventh Framework Programme (FP7/2007-2013) under grant agreement 275094. The various other funders of this long-term study are acknowledged in earlier papers.

\section{Literature Cited}

Adams, C. D. 1972. Flowering plants of Jamaica. University of the West Indies, Mona, Jamaica.

Batista, W. B., and W. J. Platt. 2003. Tree population responses to hurricane disturbance: syndromes in a south-eastern USA old-growth forest. Journal of Ecology 91:197-212.

Bellingham, P. J. 1991. Landforms influence patterns of hurricane damage: evidence from Jamaican montane forests. Biotropica 23:427-433.

Bellingham, P. J., and A. D. Sparrow. 2009. Multi-stemmed trees in montane rain forests: their frequency and demography in relation to elevation, soil nutrients and disturbance. Journal of Ecology 97:472-483.

Bellingham, P. J., E. V. J. Tanner, and J. R. Healey. 1994. Sprouting of trees in Jamaican montane forests, after a hurricane. Journal of Ecology 82:747-758.

Bellingham, P. J., E. V. J. Tanner, and J. R. Healey. 1995. Damage and responsiveness of Jamaican montane tree species after disturbance by a hurricane. Ecology 76:25622580.

Bellingham, P. J., E. V. J. Tanner, P. M. Rich, and T. C. R. Goodland. 1996. Changes in light below the canopy of a Jamaican montane rainforest after a hurricane. Journal of Tropical Ecology 12:699-722.

Boose, E. R., D. R. Foster, and M. Fluet. 1994. Hurricane impacts to tropical and temperate forest landscapes. Ecological Monographs 64:369-400.

Boose, E. R., M. I. Serrano, and D. R. Foster. 2004. Landscape and regional impacts of hurricanes in Puerto Rico. Ecological Monographs 74:335-352.

Boucher, D. H. 1990. Growing back after hurricanes. Bioscience 40:163-166.

Burslem, D. F. R. P., T. C. Whitmore, and G. C. Brown. 2000. Short-term effects of cyclone impact and long-term recovery of tropical rain forest on Kolombangara, Solomon Islands. Journal of Ecology 88:1063-1078.

Busby, P. E., G. Motzkin, and E. R. Boose. 2008. Landscapelevel variation in forest response to hurricane disturbance across a storm track. Canadian Journal of Forest Research 38:2942-2950.

Canham, C. D., J. Thompson, J. K. Zimmerman, and M. Uriarte. 2010. Variation in susceptibility to hurricane damage as a function of storm intensity in Puerto Rican tree species. Biotropica 42:87-94.

Coutts, M. P., and J. Grace, editors. 1995. Wind and trees. Cambridge University Press, Cambridge, UK.

Dietze, M. C., and J. S. Clark. 2008. Changing the gap dynamics paradigm: vegetative regeneration control on forest response to disturbance. Ecological Monographs 78:331-347.
Everham, E. M., and N. V. L. Brokaw. 1996. Forest damage and recovery from catastrophic wind. Botanical Review 62: 113-185.

Field, C. B., et al., editors. 2012. Managing the risks of extreme events and disasters to advance climate change adaptation. Cambridge University Press, Cambridge, UK.

Foster, D. R., and E. R. Boose. 1995. Hurricane disturbance regimes in temperate and tropical forest ecosystems. Pages 305-339 in M. P. Coutts and J. Grace, editors. Wind and trees. Cambridge University Press, Cambridge, UK.

Foster, D. R., D. H. Knight, and J. F. Franklin. 1998. Landscape patterns and legacies resulting from large, infrequent forest disturbances. Ecosystems 1:497-510.

Gelman, A., and J. Hill. 2007. Data analysis using regression and multilevel/hierarchical models. Cambridge University Press, Cambridge, UK.

Healey, J. R. 1990. Regeneration in a Jamaican montane tropical rain forest. Dissertation. University of Cambridge, Cambridge, UK.

Holling, C. S. 1973. Resilience and stability of ecological systems. Annual Review of Ecology and Systematics 4:1-23.

Lawrence, M. B., and J. M. Gross. 1989. Atlantic hurricane season of 1988. Monthly Weather Review 117:2248-2259.

Lin, T. C., S. P. Hamburg, and K. C. Lin. 2011. Typhoon disturbance and forest dynamics: lessons from a northwest Pacific subtropical forest. Ecosystems 14:127-143.

Lines, E. R., D. A. Coomes, and D. W. Purves. 2010. Influences of forest structure, climate and species composition on tree mortality across the Eastern US. PLoS ONE 5:e13212.

Lugo, A. E. 2008. Visible and invisible effects of hurricanes on forest ecosystems: an international review. Austral Ecology 33:368-398.

Merrens, E. J., and D. R. Peart. 1992. Effects of hurricane damage on individual growth and stand structure in a hardwood forest in New Hampshire, USA. Journal of Ecology 80:787-795.

Ogle, K., M. Uriarte, J. Thompson, J. Johnstone, A. Jones, Y. Lin, and J. K. Zimmerman. 2006. Implications of vulnerability to hurricane damage for long-term survival of tropical tree species: a Bayesian hierarchical analysis. Pages 98-117 in J. S. Clark and A. E. Gelfand, editors. Hierarchical modelling for the environmental sciences: statistical methods and applications. Oxford University Press, Oxford, UK.

Ostertag, R., W. L. Silver, and A. E. Lugo. 2005. Factors affecting mortality and resistance to damage following hurricanes in a rehabilitated subtropical moist forest. Biotropica 37:16-24.

Overpeck, I. T., D. Rind, and R. Goldberg. 1990. Climateinduced changes in forest disturbance and vegetation. Nature 343:51-53.

Papaik, M. J., and C. D. Canham. 2006. Species resistance and community response to wind disturbance regimes in northern temperate forests. Journal of Ecology 94:1011-1026.

Plummer, M. 2003. JAGS: A program for analysis of Bayesian graphical models using Gibbs sampling. Pages 20-22 in K. Hornik, F. Leisch, and A. Zeileis, editors. Proceedings of the 3rd International Workshop on Distributed Statistical Computing, (DSC 2003), Vienna, Austria, March 20-22, 2003. R Foundation for Statistical Computing, Vienna, Austria.

Putz, F. E., and R. R. Sharitz. 1991. Hurricane damage to oldgrowth forest in Congaree Swamp National Monument, South Carolina, U.S.A. Canadian Journal of Forest Research 21:1765-1770.

R Development Core Team. 2013. R: a language and environment for statistical computing. R Foundation for Statistical Computing, Vienna, Austria. www.r-project.org

Sakai, A., and S. Sakai. 1998. A test for the resource remobilization hypothesis: tree sprouting using carbohydrates from above-ground parts. Annals of Botany 82:213216. 
Scatena, F. N., and A. E. Lugo. 1995. Geomorphology, disturbance, and the soil and vegetation of two subtropical wet steepland watersheds of Puerto Rico. Geomorphology 13:199-213.

Sherman, R. E., T. J. Fahey, P. H. Martin, and J. J. Battles. 2012. Patterns of growth, recruitment, mortality and biomass across an altitudinal gradient in a neotropical montane forest, Dominican Republic. Journal of Tropical Ecology 28: 483-495.

Su, Y. S., and M. Yajima. 2012. R2jags: a package for running jags from R. R package version 0.03-08. http://cran.r-project. org/web/packages/R2jags/

Tanner, E. V. J. 1977. Four montane rain forests of Jamaica: a quantitative characterization of the floristics, the soils and the foliar mineral levels, and a discussion of the interrelations. Journal of Ecology 65:883-918.

Tanner, E. V. J., and P. J. Bellingham. 2006. Less diverse forest is more resistant to hurricane disturbance: evidence from montane rain forests in Jamaica. Journal of Ecology 94: 1003-1010.

Uriarte, M., C. D. Canham, J. Thompson, and J. K. Zimmerman. 2004. A neighborhood analysis of stem growth and survival in a hurricane-driven tropical forest. Ecological Monographs 74:591-614.

Uriarte, M., J. S. Clark, J. K. Zimmerman, L. S. Comita, J. Forero-Montaña, and J. Thompson. 2012. Multidimensional trade-offs in species responses to disturbance: implications for diversity in a subtropical forest. Ecology 93:191-205.

Vandermeer, J., I. G. de la Cerda, D. Boucher, I. Perfecto, and J. Ruiz. 2000. Hurricane disturbance and tropical tree species diversity. Science 290:788-791.
Walker, L. R. 1991. Tree damage and recovery from Hurricane Hugo in Luquillo Experimental Forest, Puerto Rico. Biotropica 23:379-385.

Weaver, P. L. 1986. Hurricane damage and recovery in the montane forests of the Luquillo Mountains of Puerto Rico. Caribbean Journal of Science 22:53-70.

Weaver, P. L. 2002. A chronology of hurricane induced changes in Puerto Rico's lower montane rain forest. Interciencia 27: 252-258.

Webb, E. L., M. van der Bult, S. Fa'aumu, R. C. Webb, A. Tualaulelei, and L. R. Carrasco. 2014. Factors affecting tropical tree damage and survival after catastrophic wind disturbance. Biotropica 46:32-41.

Webb, L. J. 1958. Cyclones as an ecological factor in tropical lowland rainforest, North Queensland. Australian Journal of Botany 6:220-228.

Wonkka, C. L., C. W. Lafon, C. M. Hutton, and A. J. Joslin. 2013. A CSR classification of tree life history strategies and implications for ice storm damage. Oikos 122:209-222.

Wunderle, J. M., D. J. Lodge, and R. B. Waide. 1992. Shortterm effects of Hurricane Gilbert on terrestrial bird populations on Jamaica. Auk 109:148-166.

Yih, K., D. H. Boucher, and J. H. Vandermeer. 1991. Recovery of the rain-forest of southeastern Nicaragua after destruction by Hurricane Joan. Biotropica 23:106-113.

Zimmerman, J. K., E. M. Everham, R. B. Waide, D. J. Lodge, C. M. Taylor, and N. V. L. Brokaw. 1994. Responses of tree species to hurricane winds in subtropical wet forest in Puerto Rico-implications for tropical tree life-histories. Journal of Ecology 82:911-922.

Zimmerman, J. K., M. R. Willig, L. R. Walker, and W. L. Silver. 1996. Introduction: disturbance and Caribbean ecosystems. Biotropica 28:414-423.

\section{Supplemental Material}

\section{Appendix A}

Map of the location of the four study sites (Ecological Archives E095-256-A1).

\section{Appendix B}

Forest site characteristics in 1984 (Ecological Archives E095-256-A2).

Appendix C

Species' relative susceptibility to hurricane damage as recorded in 1989 (Ecological Archives E095-256-A3).

Appendix D

Hurricane damage effects on stem growth rates over time (Ecological Archives E095-256-A4).

\section{Appendix E}

Hurricane damage effects on tree growth rates for the most abundant species (Ecological Archives E095-256-A5). 